junction of the inflamed and the healthy parts. On the surface of the inflamed areas of skin bullæ, from half an inch to one and $a$ half inches in diameter, were freely sprinkled. In places these bullæ were confluent. It will be observed that this case differs from Dr. Priestley's in the presence of infiltration of the skin in addition to the erythema. That, however, the disease was not erysipelas was shown by the simultaneous appearance of the dermatitis in such wide areas. Moreover, diffased acute erysipelas would almost certainly have killed the patient in a day or two. I cannot recall whether there was or not faucial inflammation. Dr. Sutton was not attending the hospital when the patient was admitted, so at my request Dr. Stephen Mackenzie kir dly saw the case. He said that it was an mmalous, but that if be were compelled to give it a name he should call it "acute pemphigus." The patient was severely, even dangerously, ill for a time, but, as far as I can remember, made a good recovery in about ten days. The cause of the illness remained obscure.

Surely cases of this kind, though rare, are well recognised. Whitehouse, in the article on Bullous Affections in "Twentieth Century Practice," describes it as "pemphigus acutus," an eruption of bulla on an erythematous base, with febrile symproms and pharyngitis. He says, however, that the bullw never exceed balf an inch in size. In Dr. Priestley's case "the smallest bullæ were as large as a hen's egg"; and in the case I have described the bullæ were also, unless my memory plays me false, far larger than those mentioned by Whitehouse. But when the line that separates a "vesicle" from a "bulla" has once been passed, variation in size depends probably on individual peculiarities of skin and on the intensity of the inflammatory process, and cannot be regarded as specific. Again, the only difference between pemphigus acutus neonatorum and the pemphigus acutus of older children and of adults, appears to lie in the absence in the former case of pharyngitis. There is the same acute outbreak of large bullæ on an erythematous base, with fever and prostration. The absence of pharyngitis in pemphigus acutus neonatorum may be due to the fact that infants appear to be exempt from catarrhal inflammation of the pharyngotonsillar region. Even in the case of the powerful poisons of syphilis and diphtheria, the stress of the inflammation falls in infants on the nasal and laryngeal mucous membranes, while the fauces are slightly if at all affected. Catarrhal pharyngitis I have never seen in a child under two years of age. The cause of these acute bullous eruptions remains undiscovered, and I have no light to shed on the subject. My excuse for writing this paper consists in my desire to bring before the profession the case already described and also one much more singular that came under my notice three years ago.

Case of acute pemphigus and acute eczema of the face in an infant, the tro direases being intercurrent, but independent in course.-The patient was a female child aged two months. Acute eczema of the face and hairy scalp of orainary type began on Jan. 28th, 1894. On Feb. 4th bullæ appeared in the groins, then on the neck, and then on the upper part of chest and back, the crop in these regions occupying three days in its development. The blebs were about half an inch in diameter and in many places confluent. Three fingers of the right hand were entirely denuded of epidermis on the morning of the 7 th. Up to this time the general condition had been good, but further blebs appeared, so that on the 9th the eruption was almost universal except on the legs, head, and face; collapse set in, and the infant was kept alive only by the free exhibition of brandy. The blebs being closely set and rupturing early, the appearance was that of an acutely inflamed skin with the epidermis hanging in shreds and patches, as in an extensive burn of the second degree. On the evening of the 9 th the child began to recover strength, but moderate fever continued till the 12th. By the $14 \mathrm{th}$ the skin was soundly healed. Meantime, on the face, on which no bullæ had appeared, the eczema had run its ordinary course. By the 14 ih the period of active secretion and crust formation was over; but sub-acute discrete papules and vesicles continued to appear for more than a month longer, the child's general bealth remaining good all the time. The child is now, at three years of age, in excellent health. Such an example of two specifically distinct skin diseases running an independent, but a simultaneous, course in the same patient is, I think, sufficiently rare to deserve being placed on record. The sanitary surroundings and the feeding (artificial) of the child at the time of the illness were all that could be desired, and no cause could be discovered. The case was an isolated one in my practice. The child's father had suffered from cute eczema in infancy; again and severely at the age of eighteen years; and is now never free from chronic eczema in winter. This fact may interest those who believe in the existence of a "dartrous diathesis."

Nagasaki, Japan.

\section{TREATMENT OF MALIGNANT TUMOURS BY MIXED TOXINS.}

BY HUGHES REID DAVIES, M.R C.S.ENG,

\section{R.C.P. LOND.}

IN an annotation in THE LANCET of Dec. 5th, 1896, there is a record of a meeting of the Johns Hopkins Medical Society, at which Dr. Coley read the results of his treatment of 160 cases of malignant tumour by subcutaneou injections of the toxins of erysipelas and bacillus prodigiosus. Dr. Culey's perseverance and patient research should merit respectful attention, even though his resulting success be so limited. I should like to draw attention to an extract from my case-book on "Coley's fluid."

A stout Jewess, married, aged fifty-three years, with a strong carcinomatous family history, consulted me in 1893 . At the axillary border of the right mamma, distinct from the gland tissue, I found a hard, clearly defined, frecly moveable mass the size of a walnut, over which the skin was unbroken. I offered to excise the growth, but consent was refused. In October, 1895, I was again consulted and noted that the tumour was distinctly nodular, the size of a hen's egg, attacbed to the skin, and moveable with difficulty. The right mamma was much swollen. The cutaneous coverings of the axillary half of the mamma were hard and cedematous. The skin over the tumour was unbroken. The axillary and clavicular gland were implicated. On Oct. 3rd Mr. F. S. Ere kindly saw the case with me We decided not to operate for many reasons, among which were : the duration of the disease from my first diagnosis in 1893; the presence of 'an adherent, ill-defined, infiltrating mass in the axilla extending under the rectoral muscles; the condition of the skin; and the strong objection of the patient's friends to any operation. The patient berself also had a horror of any attempt at surgical interference, yet craved that something might be done. As a last resource, and to satisfy the patient, subcutanous injections of Coley's fluid were commenced. On Nov. 22nd a hypodermic injection of one minim of Coley's fluid was administered about one inch from the tumour on the sternal side. There was no appreciable reaction beyond a slight blush round the tumour. On the 25th two minims of a weaker solution (equal to one minim of the previous stronger solution) were injected with no appreciable result. On the 27 th two minims were injected and resulted in rigors, followed by about one inch of slight circumferential blushing lasting twenty-four hours. The patient was mentally but not physically upset. The temperature was $101^{\circ} \mathrm{F}$. and the pulse was 90 . The odema of the skin was certainly less On Dec. 3rd three minims were administered and followed by slight rigors. On the 6 th five minims were given, which produced strong rigors, romiting, and diarrhœea (lasting two hours) within half-an-hour of the injection, which was well into the base of the tumour and not into the neighbouring skin. Four hours after the injection the temperature was $1025^{\circ}$ and the pulse was 140 ; there was no body rash, but a broad circumferential blush and axillary gland tenderness. There was great bodily and mental distress. Following this there were debility, loss of appetite, a daily temperature of from $100^{\circ}$ to $101^{\circ}$, with a pulse of from 90 to 100 , until the 14th, when another injection of four minims into the base of the tumour was given, from which there was no reaction. By this time there was not much increase in the size of the base, but the fungations were more expansive. The tumour was freely moveable. The œedema of the mamma and of the axillary folds was less. There was no inflammation or suppuration at the seat of the injections. There was no body rash and no wasting, but there were slight occasional hæmorrhages and free serous discharge from the fungating surface. On the 20 th the fungating mass was sloughing 
centrally, leaving a large cup-like cavity surrounded by large nnequal fungations. The mamma was larger and harder. Owing to objections from the patient no hypodermic injection had been given since Dec. 14th. On the 23rd three minims were injected but no reaction followed. On Jan. 11 th, 1896 , the tumour centrally had sloughed almost flush with the thorax. There was marginal increase. Four minims of fresh Coley's fluid were injected into the marginal fungations, which produced a vigorous reaction in half an hour, with rigors and romiting, followed by stupor and difficult locomotion, and succeeded by a deep sleep lasting all night. From this date to March 19 th the injections were fairly regular at intervals of a few days. There was free serous discharge from the tumour, especially from the central cavity. The marginal growths were thinning perceptibly. Rigors, and often retching or vomiting, nearly always followed the injections. The patient was daily lo:ing weight and strength, and the growth was slowly but steadily increasing in size, it then measuring four inches by three inches. An eczematous, patchy condition of the skin appeared on the forehead, eyelids, and extensor surfaces of the knees and elbows, with exfoliation. The skin of the fingers and palms cracked and peeled. At this stage, as no appreciable benefit had been derived, the injections were stayed.

On Dac. 7th, 1896, the tumour was found to extend from the angle of the right scapula to the axillary half of the right mamma, and above from the apex of the axilla to a line drawn from the lower border of the marnma to the inferior angle of the scapula. The pectorales muscles were pushed forward by the growth; the right arm was twice its normal size from codema, and the clavicular glands were markedly increased in size and hardness. The mamma itself was badly infiltrated and partly sloughing. Mitigation of the agonising pain and sleeplessness experienced by the patient was derived from morphia pills, of which she daily took up to two grains. The local treatment throughout was an endeavour to keep the fungating masses dry, sweet, and clean by various powders and antiseptic washes.

On Des, 23rd the patient became semi-comatose and, without regainiog consciousness, died on Dec. 27th, 1896. The usual Jewish objections to post-mortem examination prevented me following the case further; but external abdominal examination showed that there was immense hepatic enlargement, the lower margin almost reaching the iliac crest.

Remarks. - The value of Coley's fluid, as gathered from the foregoing notes, has been, in this case of carcinoma, I fear, practically nil. True, in the early stage of the disease I fancied the rate of growth was checked and the fœetor of the discharge lessened, but the terribly alarming reactions after injection, and the final skin effects, as noted, induced me to desist from a further course of treatment.

Bow, E.

\section{SOME REMARKS ON PLAGUE.}

\section{By J. A. LOWSON, M.B., C.M. EdIN.}

A FEW remarks on some plague questions may not be out of place at a time when Europe is threatened with invasion by an old enemy, and especially as a late paper on the subject-viz., that by Dr. Cantlie before the Epidemiological Society on Dec. 18th, 1896-contains inaccuracies regarding the Hong-Kong epidemic as well as opinions which are not shared by several of those whose experience of the disease bas been very much greater than his. Full treatment of these sabjects can scarcely be gone into, as considerations of time and space do not permit at present.

\section{Nomenclature.}

Any change in the nomenclature of the disease is greatly to be deprecated; there is really no necessity for it. In Hong-Kong those of us who were constantly cescribing the disease to medical visitors had occasion to call it a malignant polyadenitis some time before Dr. Cantlie ever saw a case. It will be time to change the name when we find that plague includes two or more diseases, as typhus fever did in days gone by. At present, however, there seems to be little danger of the name "malignant polyadenitis" taking root; one might as well apply it to syphilis as to plague.

\section{Distribution}

The present known limits of plague have not been correctly laid down by Dr. Cantlie. I have very little doubt myself that plague has made its way over Europe, Asia, and Africa in past days. In the course of desultory reading I came to the corclusion that the East Coast of Africia at least had suffered from the disease futher south than a limit of nineteen degrees north, but without medical authority at hand refrained from mertioning this at the Epidemiological Society's meeting when plague was discussed. Since that time I find that plague is well known in Equatorial Africa, and through the courtesy of Mr. Peter Rattray of Dundee, lately in Uganda, some interesting details can be given. The disease in the Uganda district is known as "kaumpuli" and is well known there. In a dictionary edited by Pilkington and printed by the Church Blissionary Society in 1892 the definition of this word is given thus :"The plague-a disease attended generally by a swelling of the glands, pain in the chest, very prevalent after the rains. Treatment: Blisters on the swollen parts and an emetic is the most successful." I understand Captain Ashburnbam of the Rifle Brigade nursed a European through the disease out there. I hope to get further information on the African distribution of the disease. When a native is attacked the whole tribe remove to another district at oncesound policy easily carried out because of its inexpensive character. Uganda is practically on the Equator, and although almost 4000 feet above the level of the sea the mean temperature should be nearer $90^{\circ}$ than $80^{\circ} \mathrm{F}$. The usual afternoon temperature in the shade is about $98^{\circ}$ in the dry season, slightly less in the rainy season. This surely does away with Dr. Cantlie's limits and the ingenious suggestion of Dr. Payne that the isothermal line of $78^{\circ}$ may stop the march of the disease. If the disease is well known in the centre of Africa it must bave found its way there; and I will not be surprised, now that attention has been directed to the subject, to hear that it is met with in other tracts of Africa. It seems peculiar that Stanley and other explorers have nothing to say on the subject, the information I had previous to Mr. Rattray's being founded on missionary lay reports on the disease.

In Singapore in the latter end of 1895 or early in 1896 the death-rate was abnormally high (from sixty to seventy-five per mille per annum) for several weeks, and some malignant disease was presumably " hanging around." The authorities there, however, reported that no plague cxisted. In 1896 three cases of plague were landed in Hong. Kong from ships arriving from Singapore, and although two cases could be explained away by long periods of incubation or other loophole, one case-that of an Indian servant on a Calcutta liner-leads me to conclude that he must have been infected in Singapore. He was perfectly well when he left Calcutta and no swellings of any kind whatever were present prior to his arrival at Singapore, yet after being on shore in Singapore he became severely ill in three days, ty pical plague glands formed, and he was landed at Hong-Kong to die Even the medical officer of health who saw the gland and had had previous plague experience did not think it was plague at first, but it was an undoubted and typical case. From the inquiries made of the man I could not trace any other source of infection, such as by fomites, \&o, on the ship. Calcutta at that time was not infected, so, if my conclusion be right, Singapore is another equatorial spot to be added to the geography of plague colonies. I trust further explanation will be forthcoming. So far, if it has been in Singapore it has not done much damage.

The evidence regarding Uganda, however, must convince us that plague will march and flourish wherever it is carried and finds a suitable pabulum-irrespectively of the ordinary temperatures we find on this earth.

\section{Pestis Minor and Pestis Ambulans.}

It is to be hoped these two terms will be kept distinct when further discussion occurs. Pestis minor is that bubonic disease which occurs (?) before an outbreak of plague, whilst pestis ambulans is the designation applied to glandular enlargements occurring during or af $t \in \mathrm{r}$ an epidemic which may probably be due to a less potent infecting power.

Ptstis minor.-The Hong. Kong experience in this respect 